\title{
A review of methods used to measure sediment resuspension
}

\author{
Jürg Bloesch \\ Swiss Federal Institute for Environmental Science and Technology (EAWAG), CH-8600 Dübendorf, \\ Switzerland
}

Key words: sedimentation, resuspension, methods

\begin{abstract}
Resuspension of bottom sediments is an important lake-internal process with regard 1.o particle cycling and sedimentation. Current methods to measure sediment resuspension are reviewed, such as optical and acoustical instruments, instantaneous multiple point water samplers, sediment trap's, sediment cores and grabs, radiotracers such as $\mathrm{Pb}^{210}, \mathrm{Cs}^{137}$ and $\mathrm{Be}^{7}$, mass balance calculations, various modelling approaches, statistical methods (correlation analysis), and laboratory experiments.

For the quantification of resuspension, the combined use of sediment traps, sediment cores, near bottom current meters, and turbidity meters to measure suspended and settling partict late matter in the hypolimnion of lakes is recommended; in addition, wind stress, seiches, slumping and sliding, and riverine input may be monitored to elucidate the mechanisms behind the process.
\end{abstract}

\section{Introduction}

Sediment resuspension, which is known to affect nutrient cycling and deposition of sediments, has long been recognized as an important lakeinternal process in large lakes, such as Neusiedlersee (Loffler, 1974), Lake Kinneret (Serruya, 1977) and Lake Erie (Charlton \& Lean, 1987). In the shallow basins of these lakes, wind driven resuspension is evident by the elevated turbidity that can be measured throughout the water column. These periods of high turbidity may be observed even during summer stratification with less turbulent hypolimnia, and where particulate matter input into the lake via large tributaries is not significant. Recently, resuspension phenomena, though minor when compared to the large resuspension events, were observed in deep and small lake basins, and where the driving wind force was not apparent (Bloesch \& Uehlinger, 1986; Bloesch \& Sturm, 1986; Lemınin \& Imboden, 1987).

Evans (1994) has dealt with the theory of resuspension, the relevant variatles such as lake depth and wind stress, and the inportance (quantification) of the process to virious water systems. The basic processes and driving forces of resuspension and sediment transportation in lakes have been described in detail, e.g., by Hakanson \& Jansson (1983), Hilton et al. (1986) and Bengtsson et al. (1990). Lanı \& Jaquet (1976) suggested that threshold curr ent velocities of $2-3 \mathrm{~cm} \mathrm{~s}^{-1}$ were sufficient to resuspend clay and silt particles, whereas sand would resuspend with $20 \mathrm{~cm} \mathrm{~s}^{-1}$, respectively. In thest: calculations, the drag coefficient is assumed to be dependent on flow conditions, particle size ard bottom roughness; i.e. strong currents $\left(\sim 20 \mathrm{~cm} \mathrm{~s}^{-1}\right)$ create 
ripple structures changing the acting forces (skin friction) on particles at the sediment surface. The ecological significance of resuspension includes impact on cycling of nutrients and contaminants (Rosa et al., 1983; Allan, 1986; Nishri, 1993; Wisniewski, 1993).

The aim of this paper is to introduce and review the methods available to measure sediment resuspension, and to suggest procedures for future research.

\section{Review of methods and results, and discussion}

The concentration of resuspended bottom sediments in the water can be directly and quantitatively measured by optical and acoustical methods. Several types of instruments are available, such as beam transmissometers and nephelometers (Gibbs, 1974; Pierson \& Weyhenmeyer, 1994), time-laps or video-cameras (Davies, 1985), infra-red sensors (Erlingsson, 1991), and highfrequency echosounders (Wright et al., 1986; Bedford et al., 1986; Thomas, 1986; Bokuniewicz etal., 1991). These instruments are either mounted on or close above the bottom sediments, or deployed from moving ships or platforms.

The optical instruments, basically, measure the light absorption (attenuation) or scattering in the lake water, and hence the temporal or spatial change in particle concentrations. Layers in the upper hypolimnion usually carry fewer particles than near bottom layers. Hence, the occurrence of turbidity and the decrease of particulate matter concentration with the distance above bottom sediments provide a good measure for the intensity of resuspension. The infra-red sensor developed by Erlingsson (1991) measures the relative elevation of the lake bottom and hence the erosion of sediments from which the amount of resuspended material can be calculated; unfortunately, infra-red light is absorbed very quickly in water, and this method can only be used in the littoral zone or shallow waters of a few meters depth.

The acoustic instruments make resuspended particles visible through echo sounding; by backscattering the signals from the particles they pro- vide the parameters for a water column mass conservation equation, with which resuspension can be quantified (Bedford et al., 1986). A modern approach is to digitalize the signals in data loggers (Pearson \& Thomas, 1991).

Unless these instruments a)e deployed at the sediment surface for an appresiable time period, the optical and acoustic methods measure the instantaneous particle concentration only, thus particular resuspension event; may not be observed. When measuring froin a moving ship, horizontal differences of resuspended particle concentration can be monitored.

An instantaneous multiple point water sampler, designed to collect undisturbed water samples at multiple heights b stween $20 \mathrm{~cm}$ and $1.8 \mathrm{~m}$ above the sediment-water interface has been used in the Laurentian Gi eat Lakes by Rosa et al. (1983). Samples are taken using horizontally operated stainless steel, and PVC pistontype bottles, driven by pneumatic cylinders, and operated by an electronic timer, controlling a solenoid valve. The supporting structure with sampler is lowered to the lake bot om, and sufficient time is allowed to elapse bejore beginning the sampling, as sediments are artificially resuspended by this activity.

Another method of estimating resuspension is the collection of sediments by a vertical series of sediment traps exposed close to the lake bottom (Rosa et al., 1983; Rosa, 198:; Hakanson et al., 1989; Rosa et al., 1991) or b $y$ comparing traps exposed just below the thermor:line with near bottom traps (Bloesch \& Uehlinger, 1986; Charlton $\&$ Lean, 1987). By using sequencing interval traps short term resuspension even s can be detected (Bloesch \& Sturm, 1986). By applying traps, a time interval of some days (us rally 1-14 days) is integrated, thus all resuspension events that occurred during trap deploymen1. are measured. As with the instantaneous measurements, the decrease in flux with distance from lake bottom provides quantitative information on sediment resuspension. However, the problem is to find the appropriate reference level, where resuspension is thought to have no effect on suspended particulate matter concentration in the water column 
above the traps. Chambers \& Eadie (1981) have shown that in large lakes a nepheloid layer, similar to that in the oceans (Sheldon et al., 1972; Biscaye \& Eittreim, 1974; Brewer et al., 1976), is fed by resuspended material and can develop to a considerable thickness.

The proposal of Gasith (1975) to correct the trap settling flux for resuspension can be used to estimate resuspension, which is the difference between uncorrected and corrected settling flux, i.e. gross (secondary matter) sedimentation minus net (primary matter) sedimentation (see eq. (1) given in Fig. 1). This method is referred to as the "label approach' by Floderus (1989) and has been modified by several authors (Charlton \& Lean, 1987; Hakanson et al., 1989; Blomqvist \& Larsson, 1992). In addition to the sediment traps, sediment cores taken by gravity corers and the sampling of suspended particulate matter above or in the vicinity of the traps are needed for this calculation. The organic content of resuspended bottom sediments, vertically settling tripton (primary flux) and entrapped sediments (secondary flux) are then used to calculate resuspension (see eqs 2 and 3 in Fig. 1). It can generally be assumed that the organic matter content in resuspended bottom sediments is lower than in fresh material. Instead of organic content of particulate matter (or $\mathrm{POC}=$ particulate organic carbon, or $\mathrm{PON}=$ particulate organic nitrogen) allochthonous titanium, aluminum, and apatite content may be used as conservative elements to calculate resuspension (Blomqvist \& Larsson, 1992). The general assumption is that refractory particulate matter content in bottom sediments is higher than in fresh material. Floderus (1989) pointed out that during periods of rapid primary sedimentation (e.g. during the spring phytoplankton bloom, often correlated with biogenic calcite precipitation), the label approach will overestimate primary flux or underestimate resuspension. This is due to the fact that both materials have the same chemical composition (referred to as rebound particles, i.e. those particles that have settled through the water column but have not become incorporated into the sediments; Walsh et al., 1988; Hicks et al., 1994).

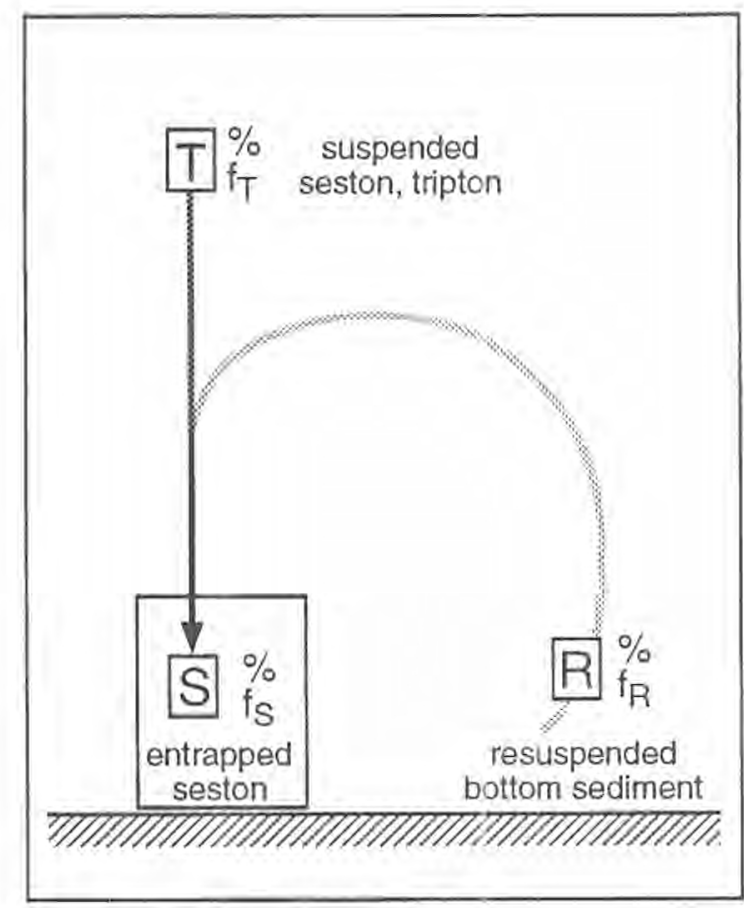

Fig. 1. Schematic view of bottom sediment resuspension measured by sediment traps exposed clo se to the lake bottom. (Modified from Gasith, 1975). $T$ = suspended tripton [mg dry weight]; $f_{T}=$ organic fraction of $\mathrm{T}[\%] ; R=$ resuspended bottom sediment [mg dry weight]; $f_{R}=$ organic fraction of $\mathrm{R}[\%]$; $S=$ entrapped settling flux [mg dry weigl $\mathrm{t}] ; f_{S}=$ organic fraction of $\mathrm{S}[\%]$.
(1) $R=S-T$
(2) $R \cdot f_{R}=S \cdot f_{i} \quad T \cdot f_{7}$
(3) $R=S \cdot \frac{\left(f_{S}-f_{T}\right)}{\left(f_{R}-f_{T}\right)}$

A most interesting methodological approach to quantify resuspension using seliment traps has been proposed by Flower (199l). He compared traps having high aspect ratio (recommended height:diameter $>5$; Bloesch \& 3urns, 1980) with traps having lower aspect ratio. Whereas the former traps measured primar/ and secondary flux, the latter traps yielded settl ng flux similar as that found in the bottom deposit: (calculated from radiometric data), i.e. the 'real' settling flux.

Occasionally, entrapped berthic and littoral organisms (Lastein, 1976) or pollen grains (Davis, 
1973) can be found in near bottom traps. Chironomid larvae in traps may indicate resuspension, however, cannot be used to quantify this flux; they may also be supplied from individuals migrating upwards from the sediments for emergence.

Another way to compare trap catches and sediment cores is by using the differences between sediment accumulation rates $\left(\mathrm{Pb}^{210}\right.$ and $\mathrm{Cs}^{137}$ dating; natural markers; varve counting) and trap settling flux (Bloesch \& Evans, 1982). Resuspension is indicated, when accumulation rates are considerably lower than trap catches. However, geochemical processes, focusing, compaction of sediments, and methodological errors of both the trap method and the dating techniques have to be taken into account. For an updated and comprehensive review of the trap and coring methods, see: Rosa et al. (1991) and Blomqvist (1992), respectively.

Long-lived and short-lived radionuclides, e.g. $\mathrm{Cs}^{137}$ (half life 30 years) and $\mathrm{Be}^{7}$ (half live 50.3 days), may be used for measuring resuspension (Cornett et al., 1994). In general, $\mathrm{Cs}^{137}$ is accumulated in the bottom sediments (Santschi et al., 1990) and fresh material has lower activity. Thus, increased $\mathrm{Cs}^{137}$ activity in suspended matter can indicate resuspension, e.g. during fall and winter turnover (Müller et al., 1991). On the other hand, $\mathrm{Be}^{7}$ is removed quickly by natural decay in the bottom sediments, whereas its activity is higher in fresh material. Hence, resuspended particles are characterized by low $\mathrm{Be}^{7}$ concentration (Cornett et al., 1994).

Studying bottom sediment resuspension by synoptic grab sampling has been proposed by Floderus (1989). On T-bottoms (zones of sediment transportation [Hakanson \&! Jansson, 1983]), the resuspended fine matter is found deposited as ephemeral mud blankets on top of the winnowed sediment surface between two resuspension events; measuring the thickness of this layer allows quantification of resuspension.

A comparison of trap catches with a mass balance determination of particulate matter (inputoutflow) allows for a quantification of resuspension, when measured settling flux of particulates exceeds the calculated retention (Dillon et al., 1990). As Evans (1994) poirted out, this approach assesses the whole lake resuspension process rather than the measurement of single episodic resuspension events.

The most sophisticated way to determine sediment resuspension is to develop models based on theoretical assumptions or a mass balance of suspended solids (Emery, 1978; Mehta et al., 1982; Lick, 1982; Aalderink et al., 1984; Kozerski, 1986; Evans \& Hakanson, 19!22). The flux of resuspension can be calculated using the concept of wind stress affecting waves and currents, or the flow induced shear stress (Aalclerink et al., 1984). In this respect, the characterization of sediments in cohesive and non-cohesive fractions is necessary. Kozerski (1986) developed a simple mathematical model to calculate $r \in$ suspension, based on the composition differences of tripton, bottom sediments and entrapped sediments as shown by the modified approach of Ga:ith (1975). Statistical methods (correlation anilysis) to compare various catchment data and field observations such as wind, lake morphometry and turbidity may also be used to calculate resuspension (Evans \& Hakanson, 1992; Hakansoll, 1994).

All these modelling approaches suffer from various fundamental assumptions, which are not fully met in-situ, such as no o: uniform horizontal transport, homogeneous res edimentation, uniform wind direction and dura ion, uniform sediment features, etc. However, these simplified models provide a good measure for estimating relative quantities of resuspended bottom sediments.

A final methodological apprisach considered in this review is the investigation of resuspension phenomena in laboratory test; under controlled conditions. For example, the shear stress is induced through water oscillation in flumes or chambers (Mehta et al., 1982; Lick, 1982; Tsai \& Lick, 1986; Brassard et al., 1594). However, the basic problem is to relate results obtained from lab tests to the extremely variable in-situ conditions. In situ-flumes (Young, 1577) may overcome some of these problems. 


\section{Conclusions}

Resuspension (and subsequent sediment transportation and resedimentation) is a phenomenon that occurs not only in large, shallow and turbulent water bodies, but also in the hypolimnion of deeper smaller lakes. The impact of bottom resuspension on lake metabolism, such as nutrient release from resuspended particles, is still not yet fully understood. Depending on the methodological approach and technology, resuspension can be directly quantified either by measuring bottom erosion and sediment redeposition, or by measuring the increase or composition in particulate matter suspension above lake bottoms. Indirect calculation of resuspension include modelling with physical parameters such as currents, waves, seiches (Gloor et al., 1994) and subsequent shear stress, or mass balance studies. Experiments in flumes and chambers can elucidate the process of resuspension.

The methods reviewed above used to quantify resuspension suggest that for in-situ studies, a combination of sediment traps, sediment cores, near bottom current meters, and turbidity meters need to be employed to best measure suspended particulate matter in the hypolimnion of lakes. Instrumented platforms combining different measurements at the same location may facilitate to investigate the causes of resuspension (Pearson \& Thomas, 1991). In addition, it is recommended to monitor wind stress, seiches, slumping and sliding, and riverine input to elucidate the mechanisms behind the process.

\section{Acknowledgements}

I thank Doug Evans, Jack Cornett, Alfred Wüest and Dave Rathke for their comments on the manuscript.

\section{References}

Aalderink, R. H., L. Lijklema, J. Breukelman, W. van Raaphorst \& A. G. Brinkman, 1984. Quantification of wind induced resuspension in a shallow lake. Wat. Sci. Tech. 17: 903-914.

Allan, R. J., 1986. The role of particulate matter in the fate of contaminants in aquatic ecosystens. NWRI Report, Scientific Series No. 142, Canada Centre for Inland Waters, Burlington, Ontario, Canada.

Bedford, K. W., O. Wai, C. M. Libicki \& M. A. Abdelrhman 1986. An acoustics based procedur: for direct measurement of sediment resuspension flux. IAGLR-86 Program, Int. Ass. Great Lakes Res. Conf., N ay 26-29, p. 24.

Bengtsson, L., Th. Hellstrơm \& L. Raloczi, 1990. Redistribution of sediments in three Swedish lakes. Hydrobiologia 192: $167-181$.

Biscaye, P. E. \& S. L. Eittreim, 1974. Variations in benthic boundary layer phenomena: Nephelc id layer in the North American Bassin. In R. J. Gibbs (ed., , Suspended Solids in Water, Plenum Press, New York: 227-260.

Bloesch, J. \& N. M. Burns, 1980. A critical review of sedimentation trap technique. Schwe z. Z. Hydrol. 42: 1555.

Bloesch, J. \& R. D. Evans, 1982. Lead-210 dating of sediments compared with accumulation rates estimated by natural markers and measured with sediment traps. Hydrobiologia 91-92/Dev. Hydrobiol. ?: 579-586.

Bloesch, J. \&. M. Sturm, 1986. Settling flux and sinking velocities of particulate phosphorus (PP) and particulate organic carbon (POC) in Lake Zug, Switzerland. In P. G. Sly (ed.), Sediments and Water Interactions, Springer, New York: 481-490.

Bloesch, J. \& U. Uehlinger, 1986. Hor zontal sedimentation differences in a eutrophic Swiss Lake. Limnol. Oceanogr. 31: 1094-1109.

Blomqvist, S., 1992. Geochemistry of coastal Baltic sediments: Processes and sampling procedures. Thesis University of Stockholm, Dept. Geology and Geochemistry, Nr. 285.

Blomqvist, S. \& U. Larsson, 1992. Petrogenic metals as tracers of resuspended and primary settling matter in a coastal area of the Baltic Sea. In Blomqvist. S., 1992: Geochemistry of coastal Baltic sediments: Processes and sampling procedures. Thesis University of Stcckholm, Dept. Geology and Geochemistry, Nr. 285: 1-37.

Bokuniewicz, H., L. McTiernan \& W. I)avis, 1991. Measurement of sediment resuspension rates in Long Island Sound. In S. Wartel (ed.), Characterizationı of mud sediments. Geo-Mar. Lett. 11: 159-161.

Brassard, P., J. R. Kramer, J. McAndrew \& E. Mueller, 1994. Metal-sediment interaction during 'esuspension. Hydrobiologia 284: 101-112.

Brewer, P. G., D. W. Spencer, P. E. Biscaye, A. Hanley, P. L. Sachs, C. L. Smith, S. Kadar dz J. Fredericks, 1976. The distribution of particulate matter in the Atlantic Ocean. Earth Planet. Sci. Lett. 32: 393-402

Chambers, R. L. \& B. J. Eadie, 1981. Nepheloid and suspended particulate matter in south-e $c$ stern Lake Michigan. Sedimentology 28: 439-447.

Charlton, M. N. \& D. R. S. Lean, 1987. Sedimentation, resuspension, and oxygen depletion in Lake Erie (1979). J. Great Lakes Res. 13: 709-723.

Cornett, R. J., L. A. Chant, B. A. Ristı \& E. Bonvin, 1994. Identifying resuspended particles lsing isotope ratios. Hydrobiologia 284: 69-77. 
Davies, A. G., 1985. Field observations of the threshold of sediment motion by wave action. Sedimentology 32: 685704.

Davis, M. B., 1973. Redeposition of pollen grains in lake sediments. Limnol. Oceanogr. 18: 44-52.

Dillon, P. J., R. D. Evans \& L. A. Molot, 1990. Retention and resuspension of phosphorus, nitrogen, and iron in a central Ontario lake. Can. J. Fish. aquat. Sci. 47: 12691274.

Emery, R. M., 1978. A theoretical expression for resuspension applied to sedimentation processes in lakes. Verh. int. Ver. Limnol. 20: 1255-1258.

Erlingsson, U., 1991. A sensor for measuring erosion and deposition. J. Sediment. Petrol. 61: 620-622.

Evans, R. D., 1994. Empirical evidence of the importance of sediment resuspension in lakes. Hydrobiologia 284: 5-12.

Evans, R. D. \& L. Hakanson, 1992. Prediction of gross and net sedimentation in small lakes. Hydrobiologia 235/236/ Dev. Hydrobiol. 75: 143-152.

Floderus, S., 1989. The effect of sediment resuspension on nitrogen cycling in the Kattegat - Variability in organic matter transport. UNGI Rapport Nr. 71, Thesis Uppsala University.

Flower, R. J., 1991. Field calibration and performance of sediment traps in a eutrophic holomictic lake. J. Paleolimnol. 5: 175-188.

Gasith, A., 1975: Tripton sedimentation in eutrophic lakes simple correction for the resuspended matter. Verh. int. Ver. Limnol. 19: 116-122.

Gibbs, R. J. (ed.), 1974. Suspended solids in water. Plenum Press, New York, 320 pp.

Gloor, M., A. Wulest \& M. Munnich, 1994. Benthic boundary mixing and resuspension induced by internal seiches. Hydrobiologia 284: 59-68.

Håkanson, L., 1994. A model to predict gross sedimentation in small glacial lakes. Hydrobiologia 284: 19-42.

Håkanson, L. \& M. Jansson, 1983. Principles of lake sedimentology. Springer, Berlin, 316 pp.

Håkanson, L., S. Floderus \& M. Wallin, 1989. Sediment trap assemblages - a methodological description. Hydrobiologia 176-177/Dev. Hydrobiol. 50: 481-490.

Hicks, R. E., Ch. J. Owen \& P. Aas, 1994. Deposition, resuspension, and decomposition of particulate organic matter in the sediments of Lake Itasca, Minnesota, USA. Hydrobiologia 284: 79-91.

Hilton, J., J. P. Lishman \& P. V. Allen, 1986. The dominant processes of sediment distribution and focusing in a small, eutrophic, monomictic lake. Limnol. Oceanogr. 31: 125133.

Kozerski, H.-P., 1986. The Lamella Model - a simple mathematical model for estimating sediment transports within a lake. Acta Hydrophys. Berlin 30: 73-89.

Lam, D. C. L. \& J.-M. Jaquet, 1976. Computations of physical transport and regeneration of phosphorus in Lake Erie, fall 1970. J. Fish. Res. Bd Can. 33: 550-563.

Lastein, E., 1976. Recent sedimentation and resuspension of organic matter in eutrophic Lake Esrom, Denmark. Oikos 27: 44-49.

Lemmin, U. \& D. M. Imboden, 1987. Dynamics of bottom currents in a small lake. Limnol. Oceanogr. 32: 62-75.

Lick, W., 1982: Entrainment, deposition and transport of fine- grained sediments in lakes. Hydrobiologia 91-92/Dev. Hydrobiol. 9: 31-40.

Loffler, H., 1974: Der Neusiedlersee. Naturgeschichte eines Steppensees. Molden, Wien, 175 pए.

Mehta, A. J., T. M. Parchure, J. G. Jixit \& R. Ariathurai, 1982. Resuspension potential of deposited cohesive sediment beds. In V. Kennedy (ed.), Estuarine Comparisons. Academic Press, New York: 591-609.

Muller, J., R. Winkler \& Ch. Sossau, Ch., 1991. Untersuchungen zur ${ }^{137} \mathrm{Cs}$-Aktivität von $\$$ chwebstoffen und zum partikulären ${ }^{137} \mathrm{Cs}$-Flux im Ammersee (Oberbayern). $\mathrm{Z}$. Wasser-Abwasser-Forsch. 24: 165- 171.

Nishri, A., 1993. Suspended sediments as a source of $P$ to summer biota of Lake Kinneret. Hydrobiologia 253/Dev. Hydrobiol. 84: 217.

Pearson, N. D. \& M. R. Thomas, 191. An instrument to measure seabed boundary-layer pro:esses. IEEE J. Ocean. Eng. 16: 338-342.

Pierson, D. C. \& G. A. Weyhenmeyer 1994. High resolution measurements of sediment resuspension above an accumulation bottom in a stratified lake. Hyclrobiologia 284: 43-57.

Rosa, F., 1985. Sedimentation and sediment resuspension in Lake Ontario. J. Great Lakes Res. 11: 13-25.

Rosa, F., J. Bloesch \& D. E. Rathk', 1991. Sampling the settling and suspended particula e matter (SPM), In A. Mudroch \& S. D. MacKnight (erls), Handbook of techniques for aquatic sediments samping. CRC Press, Boca Raton: 97-130.

Rosa, F., J. O. Nriagu, H. K. T. Wong \& N. M. Burns, 1983. Particulate flux at the bottom of l.ake Ontario. Chemosphere 12: 1345-1354.

Santschi, P., S. Bollhalder, S. Zing; \& K. Farrenkothen, 1990. The self-cleaning capacity of surface waters after radioactive fallout. Evidence from European waters after Chernobyl, 1986-1988. Envir. Sci. Technol. 24: 519-527.

Serruya, C., 1977: Rates of sediment:tion and resuspension in Lake Kinneret. In Interactions tetween sediments and freshwater. Proc. int. Symp. Dr W. Junk Publishers, The Hague: $48-56$.

Sheldon, R. W., A. Prakash \& W. 1. Sutcliffe, Jr., 1972. The size distribution of particles in the Ocean. Limnol. Oceanogr. 17: 327-340.

Thomas, Y. F., 1986. Etude des trar sports de matières en suspension en Manche par l'emploi de l'imagerie CZCS. La Baie de Seine, Coll. Nat. CNRS, 24-26 Avril 1985: 173182.

Tsai, C.-H. \& W. Lick, 1986. A portc ble device for measuring sediment resuspension. J. Great Lakes Res. 12: 314321.

Walsh, I., K. Fischer, D. Murray \& .. Dymond, 1988. Evidence for resuspension of rebound particles from nearbottom sediment traps. Deep Sea Ies. 35: 59-70.

Wisniewski, R., 1993. The release of phosphorus during sediment resuspension. Hydrobiologia 253/Dev. Hydrobiol. 84: 321-322 (Abstract).

Wright, L. D., J. D. Boon, M. O. Gre en \& J. H. List, 1986. Response of the mid shoreface of the southern Mid-Atlantic Bight to a 'northeaster'. Geo-Mar. Lett. 6: 153-160.

Young, R. A., 1977. Sea flume. A device for in situ studies of threshold erosion velocity and e osional behaviour of undisturbed marine muds. Mar. Gєol. 23: M11-M18. 